Portland State University

PDXScholar

$11-16-2018$

\title{
Risk Communication in Lactation Consulting
}

Stephanie Elliott

Portland State University

Follow this and additional works at: https://pdxscholar.library.pdx.edu/honorstheses Let us know how access to this document benefits you.

\section{Recommended Citation}

Elliott, Stephanie, "Risk Communication in Lactation Consulting" (2018). University Honors Theses. Paper 647.

https://doi.org/10.15760/honors.662

This Thesis is brought to you for free and open access. It has been accepted for inclusion in University Honors Theses by an authorized administrator of PDXScholar. Please contact us if we can make this document more accessible: pdxscholar@pdx.edu. 


\title{
Risk Communication in Lactation Consulting
}

\author{
by \\ Stephanie Elliott
}

An undergraduate honors thesis submitted in partial fulfillment of the

requirements for the degree of

Bachelor of Science

in

University Honors

and

Health Sciences

Thesis Advisor

Julia Goodman, PhD

Portland State University

2018 


\section{Risk Communication in Lactation Consulting}

Stephanie Elliott

OHSU-PSU School of Public Health

Thesis advisor: Julia Goodman, PhD

\section{Abstract}

Breastfeeding has well-established benefits for lifelong health, and public health initiatives have long concerned themselves with increasing breastfeeding rates. There is a debate within the lactation community about whether breastfeeding promotion should emphasize the benefits of breastfeeding or the risks of formula feeding. Benefit-based messaging is the established norm in both public health campaigns and interpersonal counseling by health professionals. Proponents of risk-based messaging point to breastfeeding as the biological norm and argue that formula feeding should always be situated against the norm of breastfeeding. In order to understand the philosophical underpinnings of riskmessaging, the efficacy of each method, and which method lactation consultants prefer, I conducted an extensive multidisciplinary literature review, interviews with lactation education program students and instructors, and a survey of 169 US-based International Board Certified Lactation Consultants (IBCLCs). Research in communication and psychology theory show little or no demonstrable benefit to the use of risk-based communication and, in situations where self-efficacy is low, it may actually increase risky health behaviors and decrease breastfeeding. Survey and interview results show that IBCLCs either favor benefit-based message framing or modify their message framing depending on who they are speaking with. The conclusion of this paper is that emphasis should be placed on decreasing barriers to breastfeeding and promoting overall justice and equity for families as opposed to messaging to persuade people to breastfeed, and in particular, emphasis on risk should be avoided with vulnerable populations. 


\section{Introduction}

It is widely agreed upon that breastmilk is the ideal first food for infants and that increasing breastfeeding rates is a worthwhile public health initiative (Surgeon General, 2011). Breastfeeding confers immunological benefits to infants through secretory $\lg A$, the presence of $\lg \mathrm{M}$ and $\lg G$ antibodies that transfer immunity from the mother, and by developing the microbiome (Newburg \& Walker, 2007). These factors quickly work to develop the immune system, resulting in a reduction in gastrointestinal tract, respiratory, and middle ear infections amongst breastfed infants (Duijts, Jaddoe, Hofman \& Moll, 2010; Ip, Chung, Raman, Trikalinos \& Lau, 2009). Breastfeeding reduces the risk of sudden infant death syndrome (SIDS), likely due to differences in levels of arousal in breastfeed infants (Hauck, Thompson, Tanabe, Moon \& Vennemann, 2011; Horne, Parslow \& Harding, 2004). Breastfeeding reduces the risk of obesity in children, especially amongst those who are born to obese mothers who are at particularly high risk for childhood obesity (Baker, Michaelsen, Rasmussen \& Sørensen, 2004). Breastfeeding also confers benefits to the mother. Studies show that breastfeeding results in greater weight loss and decreases in metabolic and cardiovascular disease amongst women who have breastfed (Baker et al., 2008; Schwartz, et al., 2010; Owen, Whincup \& Cook, 2011). Additionally, breastfeeding reduces the lifetime risk of breast and ovarian cancers (Collaborative group, 2002, Ip et al. 2009). These benefits illustrate the value of increasing breastfeeding rates for the health of our population. Breastfeeding rates are largely influenced by public policy, such as maternity leave, social support, breastfeeding promotion and awareness, cultural norms, family support, and the direct support that families get in the time leading up to and following birth by their healthcare team, including 
International Board Certified Lactation Consultants (IBCLCs) (Thulier \& Mercer, 2009). Within the field of breastfeeding promotion and advocacy, there are ongoing debates about the best way to encourage families to choose breastfeeding. One such debate is about the way that breastfeeding promotion messages are framed. Is the best way to increase breastfeeding rates to advise childbearing families about the benefits of breastfeeding or to emphasize the risks of formula feeding? Proponents of risk-based messaging argue that breastfeeding is the norm and formula is the "intervention" and that our language should always reflect that perspective. They argue that risk-based messages encourage parents considering feeding their children formula to see the risk of adverse health outcomes associated with that choice rather than perceiving breastfeeding as a way to gain added benefits.

There are three major domains in which message framing about breastfeeding plays a significant role:

1) Research: Articles about breastfeeding are often framed to highlight the positive health outcomes associated with breastfeeding, rather than negative outcomes associated with formula feeding. For example, the title of the study might highlight a reduction in asthma associated with breastfeeding or might claim that breastfeeding has a protective effect against breast cancer, rather than saying that not breastfeeding increases asthma or cancer risk (Smith, Dunstone \& Elliott-Rudder, 2009). It is also common for formula fed infants or non-breastfeeding women to be the control group in these studies and for the breastfeeding babies or mothers to be the intervention or exposure group (Duijts et al, 2010). Many authors have argued that breastfeeding babies should make up the control 
group and formula fed babies should be the intervention group, centering breastfeeding as the biological norm (Smith, 2009, ILCA, 2011). However, from a practical methodological standpoint there are benefits to using formula-fed babies as the control group. Breastfeeding exists on a continuum and having been breastfed once does not have the same health impacts as having been breastfeed for a year. As such, breastfeeding groups are often categorized by exclusivity and duration of breastfeeding and are compared with control groups of infants who have never been breastfed. This allows researchers to understand the magnitude of the impacts based on duration and level of exclusivity, and whether there are limits to the effect over time.

2) Public health campaigns: Breastfeeding promotion has generally been considered a significant and worthwhile public health initiative, and marketing materials are a key aspect of that. Breastfeeding promotional materials commonly report the benefits of breastfeeding rather than using risk-based messaging. Some argue that this normalizes formula feeding and does not portray accurately what the effects of choosing to formula feed rather than breastfeed are.

3) Interpersonal counseling by healthcare providers: Healthcare providers have a significant influence over their patients' feeding choices. Many argue that, when counseling patients, care providers should refer to the risks of formula feeding, rather than highlighting the benefits of breastfeeding, again, centering breastfeeding as the norm. This domain is the primary concern of this research paper.

While there may be a strong philosophical argument to be made for centering breastfeeding as the normative method of infant feeding, the context in which people are 
making decisions about how to feed their babies is murky and complex. There are many social, economic, historical, political and cultural issues to consider, in addition to the fundamental question of whether risk-based messaging is effective. What is the evidence to suggest that emphasizing risks persuades more people to choose to breastfeed? How does risk-based language impact the way that individuals perceive the message? How might those perceptions impact the individual's choices? What are the moral implications of using maternal guilt as a tool to encourage breastfeeding, particularly when the logistics and economics of breastfeeding can be difficult for many families? Alternately, is a failure to emphasize the risks of formula feeding over concerns about eliciting feelings of maternal guilt paternalistic? Is an emphasis on the benefits of breastfeeding a misrepresentation of the truth?

Through a thorough literature review, this article will examine the theoretical aspects of risk messaging and evaluate the evidence about what is actually effective at increasing breastfeeding rates. Additionally, it will plunge into the discourse about the ethical considerations of risk-based messaging. After getting a sense of the debate within the lactation and breastfeeding promotion community, a survey of US-based IBCLCs will provide an understanding of what lactation professionals are actually doing and what factors have informed their decision-making. This information will be supplemented with interviews with lactation program educators and students, to provide insight into what is being taught and discussed on the subject in classrooms. 


\section{Background}

Perhaps the best way to understand the issues involved in risk-based communication is to track the discourse amongst lactation professionals, academics and others who concern themselves with breastfeeding promotion. Contextually, it is important to understand that over the course of the 20th century, the movement of women into the

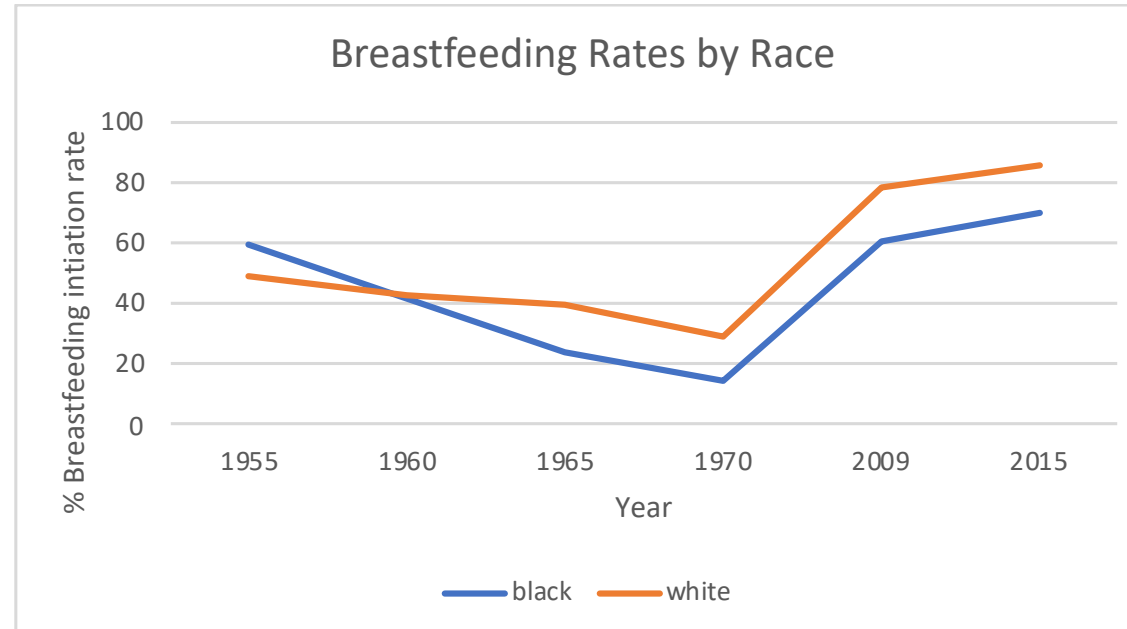

Figure 1: US breastfeeding rates by race1955-2015

*1955-1970 rates by Hirshman \& Hendershot \& 2009-2015 rates from CDC workforce, aggressive marketing campaigns by formula companies, and sexualization of breasts in popular culture created a shift in cultural norms, causing formula feeding to replace breastfeeding as

the normative way of feeding babies. By the mid-twentieth century formula feeding was seen as the scientifically-based, most convenient, modern and sophisticated way to feed a baby, and that attitude was reflected in the social and racial divides in breastfeeding rates (Institute of Medicine, 1991). Between 1951 and 1955 59\% of firstborn children born to black women were breastfed, whereas only $49 \%$ of babies born to white women were. By the 1970 s overall numbers of women breastfeeding had dramatically dropped but the proportions had also inverted so that only $19 \%$ of black women were breastfeeding firstborn children, whereas $29 \%$ of white women were. In the 1950's educational attainment was positively associated with formula feeding, but by the 1970's the more educated were moving back to breastfeeding. Regardless, the overall breastfeeding 
initiation rates were under $50 \%$ for all ethnicities and all but the most highly educated group in 1970 (Hirschman \& Hendershot, 1979). The feminist movement of the 1960s and 70 s began to reclaim breastfeeding as a healthy normal part of childbearing for educated white women whose breastfeeding rates have continued to climb since their low-point in the 1970s. However, the damage had been done amongst the less educated and women of color, whose recovery from these newly established norms has not been nearly as successful. According to the Centers for Disease Control, in 2015 black Americans were the least likely to breastfeed, with an initiation rate of $69 \%$ and only $44 \%$ of black babies being breastfeed at 6 months of age, compared with $86 \%$ and $62 \%$ amongst white women, respectively. Education level is an even stronger predictor of breastfeeding, with an initiation rate of $92 \%$ for college graduates, compared to $73 \%$ amongst those with just a high school diploma (Centers for Disease Control, 2015).

It was with this context in mind in 1996 that Diane Wiessinger wrote an often-cited article on risk-based language. She bristled against the way in which lactation professionals and healthcare providers had accepted that formula feeding was the norm and challenged them to present their information differently, centering breastfeeding as the normative way of feeding a baby. Considered a seminal essay on the topic, "Watch Your Language!" outlines the argument as follows:

We must not let inverted phrasing by the media and by our peers go unchallenged. When we fail to describe the hazards of artificial feeding, we deprive mothers of crucial decision-making information. The mother having 
difficulty with breastfeeding may not seek help just to achieve a "special bonus;" but she may clamor for help if she knows how much she and her baby stand to lose. She is less likely to use artificial milk just "to get him used to a bottle" if she knows that the contents of that bottle cause harm (Wiessinger, 1996).

This framing has been embraced by many lactation consultants, organizations and publications. The International Lactation Consultant Association's 2011 publication "The Risks of Not Breastfeeding" reiterates Wiessinger's view that breastfeeding is the normative method of infant feeding and uses risk-based language throughout. The document also puts forward the aforementioned argument that study design should always use breastfeeding dyads as the control group in research and the formula feeding group should always be the intervention or exposure group.

Given the movement away from breastfeeding over the course of the twentieth century, it makes sense that lactation consultants would lead the charge in rewriting the narrative about breastfeeding. The complicating factor of this reclamation of breastfeeding as the norm is the educational and racial divide in breastfeeding rates. Breastfeeding is the biological norm, to be sure, and has once again become the cultural norm for educated white women, but people are not breastfeeding their babies in a vacuum. Lack of family support or limited exposure to breastfeeding decrease the likelihood that an individual will breastfeed. Breastfeeding can be challenging and painful and adequate support in the immediate postpartum are crucial to breastfeeding continuation. The United States offers 
no guaranteed paid maternity leave, causing many women to be forced to return to work shortly after giving birth, requiring them to begin the cumbersome process of pumping and bottle feeding before breastfeeding is well established (Surgeon General, 2011). Would treating breastfeeding as the norm when speaking to people for whom — at least culturally - it is not cause those people to see it as the most normal and desirable option, or would it highlight a chasm between the individual and the care provider?

Advocates for risk-based messaging argue that, when studying or advising about other health behaviors such as smoking cessation or eating habits, biological norms, not cultural, are always used (Wiessinger, 1996). However, there have been studies researching the impacts of gain-framed appeals in smoking cessation campaigns. These studies have found that both the degree of nicotine dependence and quitting intentions moderate the impacts of gain-framed and loss-framed messaging. Essentially, for those with a lower tobacco dependence and those without intention to quit smoking, gainframed messages (i.e. the benefits of quitting smoking) are more effective (Moorman \& van den Putte, 2008). Another study found that there was a difference between how people of different genders responded to smoking cessation messages. For women, gainframed smoking cessation messages were more encouraging and were positively correlated with length of time to relapse (Toll et al., 2008). These examples show a precedent in other areas of health messaging for an emphasis on more positive and aspirational, rather than risk-based, messaging, and demonstrate how people's identities, contexts, and self-efficacy impact the effects of message framing. 
Perhaps the most interesting way to track the discourse on this topic is through the writing of a physician named Alison Stuebe. Dr. Stuebe is an obstetrician and gynecologist, and assistant professor at the Gillings School of Global Public Health at the University of North Carolina. In a post on the Association of Breastfeeding Medicine blog entitled "Might there be risks of risk-based language?" (2016) Stuebe traced her own evolving perspective on the issue. Earlier in her career, she was an adamant advocate for the risk-based framing of formula feeding in interpersonal counseling, breastfeeding advocacy, and research. She referred back to a 2010 blog post that she wrote in support of Wiessinger's 1996 article. Her closing sentence in that article read: "There are no benefits of breastfeeding. There are risks of formula feeding." Stuebe's research articles from that period reflected that perspective, always framing breastfeeding as the norm, highlighting the increased risks to mothers and babies associated with not breastfeeding. Stuebe's 2016 blog post uses a variety of research -much of which served as the jumping-off point for the literature review in this paper- and discursive points to challenge her previously held beliefs. Stuebe points to the fraught context in which women are making decisions about how they feed their babies, how that may impact their perceptions of risk, and how riskbased messages are received. She argues that, for mothers who are facing the risk of their sons being gunned down in the streets, the risks of formula feeding might sound much less urgent. She also highlights the way that an individual's self-efficacy might impact the way risk-based messages are perceived and may further create guilt in the lives of women whose options for feeding are limited. Stuebe also argues that an emphasis on the risks of formula feeding may create undue stress in the large proportion 
of women who ultimately need to supplement their babies with formula or may cause them to go through an incredible amount of stress to avoid supplementation, thereby placing a higher value on breastfeeding exclusivity than upon maternal mental health. Stuebe points to high breastfeeding initiation rates and poor continuation rates as an indication that breastfeeding intention is not the problem. People want to breastfeed; they just don't have the means or support to do so.

Stuebe's article is a departure from the dominant discourse in lactation. It fits more comfortably within intersectional feminist critiques of breastfeeding promotion, and within public health discourse about the social determinants of health. Frustration with the sometimes guilt-inducing 'breast is best' breastfeeding promotion narrative has spawned a counter-movement. The 'fed is best' movement is a backlash against what is perceived as militant pro-breastfeeding campaigns that have driven women to extreme measures to avoid the provision of formula to their infants. The movement has capitalized on some alarming media stories about infants who died from starvation after poor breastfeeding management in the hospital and discharge without adequate follow-up (Fed is Best Foundation, 2018). While Stuebe's arguments are not at all an endorsement of the 'fed is best' movement, she does outline the context from which a movement like that might arise. If women are driven to desperate measures to avoid formula feeding, it's natural that some might reflect on those experiences and wonder whether the risk trade-off really made sense. Was the preservation of exclusive breastfeeding worth the compromises in mental health, the huge amount of time pumping, the money spent on lactation consultants, or delayed returns to work? 


\section{Literature Review \& Theoretical Framework \\ Communication Theory and Risk-Based Appeals}

Psychological and communication theories provide a theoretical framework to understand how people might interpret differently framed messages and make decisions based on those messages. Prospect theory is a model that predicts how people will engage in positive health behaviors in response to gain-framed or loss-framed messaging (Kahneman \& Tversky, 1979). In the context of this paper gain-framed messages would be those espousing "the benefits of breastfeeding." Loss-framed messages are those that refer to "the risks of formula feeding." According to prospect theory, loss-framed messages are more effective for encouraging individuals to pursue a behavior that involves some risk, whereas the gain-framed messages are most effective for encouraging less risky health behaviors. An example of a health behavior that is considered risky is a screening test, because there is a risk of a positive screen. Low risk behaviors are preventive health behaviors such as brushing your teeth or eating fruits and vegetables. Prospect theory suggests that messages about your risk of breast cancer would be more likely to persuade you to pursue mammography than would positive messages about breast health. Messages about the benefits of good oral hygiene are more persuasive to influence you to brush your teeth than those highlighting the risks of not brushing. As a health behavior, however, it is difficult to classify breastfeeding. By this definition, breastfeeding should be considered a low-risk behavior since it is a preventive health behavior and there is no risk of a diagnosis arising from it; however, it bears its own unique risks. There is a risk of pain or discomfort, stigma, and possibly workplace 
difficulties due to the need to express breastmilk after returning to work. It is not as simple and effortless as brushing your teeth. If breastfeeding is to be considered to be a low risk behavior, prospect theory would indicate that gain-framed or benefit-based messages would be most encouraging; however, if it is considered a higher risk behavior, lossframed or risk-based messaging would result in more people breastfeeding.

Ultimately, when tested, prospect theory doesn't necessarily hold true. A meta-analysis of 93 studies by O'Keefe and Jensen in 2007 indicated that the only context in which benefit-framed messages consistently resulted in better health behaviors was related to oral hygiene, and the only situation where there was consistently an improvement of health behaviors with loss-framed messaging was in the case of breast cancer screening. There were otherwise no statistically significant differences between health behaviors associated with each messaging type.

Another theoretical model that could be applied to health messaging is fear-appeal theory. Fear-appeal theory posits that threatening communication is the most likely to cause a behavioral change. Within that, there are theories describing two significant moderators of behavior change: 1) Perceived susceptibility to the threat and 2) Perceived selfefficacy, which is the ability to avoid the threat or enact the behavior change (Peters, Ruiter \& Kok, 2013). The latter is particularly relevant to the discussion of breastfeeding. There are significant obstacles to breastfeeding for American women. Lack of family support, lack of prenatal breastfeeding education, limited exposure to breastfeeding, and lack of paid maternity leave all may diminish a person's perceived breastfeeding self- 
efficacy (Surgeon General, 2011). Some research testing fear-appeal theory has determined that perceived susceptibility and self-efficacy did not moderate behavior change, rather that severity of threat was the only factor that amplified or diminished behavior change. However, Peters et al. conducted a critical meta-analysis of this research controlling for significant outcome bias $^{1}$ and the intention-behavior gap ${ }^{2}$ and found that not only could low self-efficacy and high perceived susceptibility moderate response to threatening messages, they could cause the person to engage in a defensive denial or downplaying of the threat, and potentially cause even greater risk-taking. They concluded that "[t]hreatening communication should exclusively be used when pilot studies indicate that an intervention successfully enhances self-efficacy." This would indicate that risk-based language should only be used in a context where predictors of successful breastfeeding are in place, such as familial and community support, prenatal breastfeeding education, adequate maternity leave, and access to lactation support, or when the intervention itself includes actions to improve breastfeeding self-efficacy.

\section{Risk-Based Messaging and Breastfeeding}

Ultimately, these theories need to be specifically tested with breastfeeding. Does riskbased message framing actually result in higher rates of breastfeeding intention? Unfortunately, there is little research to this end. One study by Wallace and Taylor examined feeding intentionality before and after exposure to risk and benefit-framed messages in 309 women. 135 were exposed to messages emphasizing the benefits of

\footnotetext{
${ }^{1}$ Significant outcome bias is a result, Peters et al. report, of publication bias, particularly related to fearappeal theory. Null findings are rarely published and therefore underrepresented.

2 The intention-behavior gap refers to the coupling of intention and behavior, when in reality intention is only predictive of behavior $1 / 3$ of the time (Peters, et al.)
} 
breastfeeding, another 135 were exposed to messages emphasizing the risks of formula feeding, and 39 served as the control, having received no informational materials at all. They found that there was no discernable difference in feeding intentionality before and after having received the messages, nor between the risk-based message group, the benefit-based message group, or the control. However, there was a significant difference in the way that the messages were received by the two intervention groups. Risk-based messaging was rated less favorably by the participants than the benefit-framed text, indicating that risk-based messaging may actually undermine trust in the message due to negative feelings towards the source material. In their discussion of the findings, Wallace \& Taylor suggested Kukla's (2006) knowledge-threshold effect as a possible explanation for the lack of impact in the different messages. Kukla points to the ubiquity of breastfeeding promotional material and argues that it has ensured that the general population is aware of the benefits of breastfeeding and that, by the time individuals are receiving more pointed breastfeeding information, they already have their intentions established.

\section{Ethical and Feminist Critiques of Risk-Based Messaging}

The crux of the ethical conundrum about breastfeeding promotion is the one brought up by Steube in her "Might there be risks of risk-based language?" essay. Relatively high breastfeeding initiation rates followed by a steep decline in the number of infants being breastfeed at six and 12 months indicate that breastfeeding intention is not at the core of low U.S. breastfeeding rates. The social determinants of health are a growing focus in public health. There is an increasing understanding that race, class, geographic location 
and other social factors underlie the risk of disease and it is perhaps more effective to focus on addressing social issues than on campaigns targeting health behaviors. Poverty, racism, misogyny, and poor social infrastructure for American mothers may be the root of America's breastfeeding problem. As the Peters et al. article concludes, risk-based messaging should be accompanied by measures that increase self-efficacy. In order to increase self-efficacy, systemic and social barriers to breastfeeding initiation and continuation need to be addressed. Paige Hall Smith (2018) argues for a social justice approach to breastfeeding, outlining seven conceptual domains. One notable domain within the framework is the notion of breastfeeding as a right. She writes that:

The right to breastfeed extends beyond the idea of a choice; social protection and support measures are needed to empower women and families with the knowledge, resources, and support needed to actualize their right to breastfeed and consider the linkages between individuals' reproductive self-determination and the conditions within their own communities (Smith, 2018).

She also lists "advancing breastfeeding as a cornerstone of health equity" as one of the domains. Smith suggests that increasing breastfeeding will improve health equity, but she also asserts that inequity is a contributing factor to low breastfeeding rates. Breastfeeding promotion and a holistic improvement in the status of women and addressing social, racial and economic inequities are parallel and symbiotic initiatives. Simply being given the choice to breastfeed is not adequate. It is necessary provide the social and structural support that women need within their communities to allow that choice to become viable. Smith highlights the multitude of often conflicting expectations that people are expected 
to grapple with when choosing how to feed their babies. The urging to breastfeed places a very real physical demand on women's bodies. The expectation of bodily sacrifice conflicts with society's demand that women recover from birth and return to the workforce. Perceptions of femininity associated with breastfeeding, the sexualization of breasts, and the perception that breastfeeding is gross or dirty are all at odds. Women are expected to breastfeed, but to do so privately. Understanding that people are choosing how to feed their babies within this fraught context, it is easier to see how it is not a simple choice. It also highlights how factors such as gender identity, race, and class intersect to complicate the decision about how to feed your baby. A social justice approach to breastfeeding addresses oppression, social inequity, unequal access to lactation support, and the social systems that put constraints on families' lives, rather than placing an emphasis on persuading individuals to choose to breastfeed.

Approaching breastfeeding from a social justice lens does not include the use of guilt or shame to influence people to breastfeed. As Stuebe (2016) highlights, there will always be a certain number of people for whom exclusive breastfeeding will be impossible, due to lactational insufficiency or other medical issues. The need for supplementation may cause those women to experience guilt for having to supplement in a situation that is beyond their control. Arguably, the barriers within individuals' own social contexts are as prohibitive as a physiological barrier to breastfeeding and could create an even greater sense of guilt due to the illusion of a choice. In a text about health message design, Monique Mitchell Turner (2012) suggests that guilt appeals are indicated only when the behavior harms others and the behavior is controllable. Some may argue that making a 
choice not to breastfeed harms the baby, but, again, is the behavior controllable when social support for breastfeeding is minimal and barriers are high? It is commonly stated, even by the World Health Organization, that virtually all women can breastfeed. Whether or not this is actually physiologically the case is debatable, but certainly from a social justice standpoint, it is not the case in America right now. However, this pervasive attitude about breastfeeding establishes an inability or unwillingness to breastfeed not only as a personal failure but as a moral failure. This moral imperative to breastfeed is explored by Taylor and Wallace in their article "For shame: Feminism, breastfeeding advocacy, and maternal guilt" (2012). They argue that, while it is not the intention of breastfeeding advocates to instill a sense of guilt in mothers, the idealization of breastfeeding as a defining feature of what it means to be a good mother, and the near irreversibility of the decision to stop breastfeeding, combined with the huge barriers to breastfeeding in American society, result in a guilt and shame that have no utility. Intentionally or not, an emphasis on risk-based message framing is a contributing factor in maternal guilt, and, arguably, weaponizes maternal guilt to persuade mothers to choose breastfeeding.

While the current body of evidence about the efficacy of risk-based massaging to influence people to breastfeed is limited, so far it does not indicate that it is likely to be effective, particularly amongst those with low breastfeeding self-efficacy. It does, however, seem to be likely to cause people to have negative feelings or mistrust towards the messaging source. Critical feminist and social justice perspectives on breastfeeding promotion suggest that guilt-oriented messaging towards already taxed and unsupported 
mothers is unethical, and that pro-breastfeeding initiatives should be directed at addressing systemic, social, and cultural barriers to breastfeeding.

\section{Methods}

To best understand what currently practicing US-based IBCLCs are doing, I conducted a survey of 169 US hospital-associated ${ }^{3}$ IBCLCs using Qualtrics web-based survey software and distributed it via the Facebook pages of regional lactation professional organizations across the United States, as well as some online community groups. Respondents answered three qualifying questions to participate in the survey, confirming that they were a currently practicing IBCLC working primarily in a U.S. hospital-associated setting. Respondents then answered questions about their counseling practices and beliefs. There were 17 questions in total and the survey was expected to take six minutes. I examined the frequency and percentage of respondents who reported using risk-versus benefit-based language, how respondents were trained, and how their messages have changed over time. I asked for the beliefs behind their decisions and what influenced any changes. I cross-tabulated results to identify how different factors may have influenced one another and what they indicated about how beliefs around breastfeeding are shaped.

To supplement the survey findings, I interviewed a lactation educator and two lactation students in local lactation programs in Portland, Oregon, to gather a more nuanced view of current practices in lactation education programs and the body of evidence being used to support their choice. Interviews were audio-recorded and transcribed. All human

\footnotetext{
${ }^{3}$ Working in an inpatient hospital setting or in an outpatient, hospital-associated clinic
} 
subjects research was approved by Portland State University's Institutional Review Board.

\section{Results}

\begin{tabular}{|l|r|r|}
\hline Total Participants & $\mathbf{n}=\mathbf{1 6 9}$ & \\
\hline Work setting: & & \\
\hline Hospital inpatient & 148 & $87.6 \%$ \\
\hline Hospital associated outpatient & 21 & $12.4 \%$ \\
\hline Additional Credentials Held: & & \\
\hline RN/BSN & 124 & $73.4 \%$ \\
\hline MSN & 12 & $7.1 \%$ \\
\hline RD & 4 & $2.4 \%$ \\
\hline Other & 29 & $17.2 \%$ \\
\hline None & 18 & $10.7 \%$ \\
\hline Duration of practice: & & \\
\hline $0-5$ years & 77 & $45.6 \%$ \\
\hline $6-10$ years & 41 & $24.3 \%$ \\
\hline $11-15$ years & 16 & $9.5 \%$ \\
\hline $16-20$ years & 18 & $10.7 \%$ \\
\hline $21-25$ years & 11 & $6.5 \%$ \\
\hline More than 25 & 6 & $3.6 \%$ \\
\hline
\end{tabular}

205 people responded to the IBCLC survey. 179 met selection criteria. 169 of those completed the survey in its entirety. The respondents overwhelmingly possessed nursing degrees (73.4\%) and most had been in practice fewer than ten years (69.9\%). Most worked primarily in an inpatient hospital setting (87.6\%).

The survey found that very few IBCLCs favored risk-based communication (3.0\%).

Table 1: Participant characteristics Many used benefit-framed messaging $(37.3 \%)$, and some used a blend of the two indiscriminately and in equal measure $(13.0 \%)$; however, the majority varied their language depending on who they were speaking with (46.8\%) (Table 2).

\begin{tabular}{|c|c|c|c|c|c|c|c|c|c|c|c|c|}
\hline \multirow{3}{*}{$\begin{array}{l}\text { Which method do you primarily use? } \\
\text { The benefits of breastfeeding }\end{array}$} & \multicolumn{10}{|c|}{ Which did your education program direct you towards } & \multirow[b]{2}{*}{ Total } & \\
\hline & \multicolumn{2}{|c|}{ Benefits of $B f$} & \multicolumn{2}{|c|}{ Risks of $\mathrm{FF}$} & \multicolumn{2}{|c|}{ Disc'd pros/cons } & \multicolumn{2}{|c|}{ Didn't discuss } & \multicolumn{2}{|c|}{ Don't remember } & & \\
\hline & 19 & $30.1 \%$ & 5 & $7.9 \%$ & 19 & $30.2 \%$ & 7 & $41.2 \%$ & 13 & $20.6 \%$ & 63 & $37.3 \%$ \\
\hline Risks of formula feeding & 1 & $20.0 \%$ & 1 & $20.0 \%$ & 0 & $0.0 \%$ & 2 & $40.0 \%$ & 1 & $20.0 \%$ & 5 & $3.0 \%$ \\
\hline Both Interchangably & 13 & $59.1 \%$ & 4 & $18.2 \%$ & 3 & $13.6 \%$ & 0 & $0.0 \%$ & 2 & $9.1 \%$ & 22 & $13.0 \%$ \\
\hline Depends who I'm talking to & 28 & $35.4 \%$ & 16 & $20.3 \%$ & 13 & $16.5 \%$ & 8 & $10.1 \%$ & 14 & $17.7 \%$ & 79 & $46.8 \%$ \\
\hline & 61 & $36.1 \%$ & 26 & $15.4 \%$ & 35 & $20.7 \%$ & 17 & $10.1 \%$ & 30 & $17.8 \%$ & 169 & \\
\hline
\end{tabular}


Depending on how they answered, respondents were prompted to list their primary reason for using their respective approaches. For those who favored benefit-framed messaging, most (57.8\%) indicated that they did so because they preferred to be positive and encouraging, while some $(22.2 \%)$ reported that they felt it was the most effective way to persuade people to breastfeed. Only 5 IBCLCs reported using primarily risk-based language. All but one reported that this was because they felt that breastfeeding was the biological norm and wanted to reflect that in their framing, while the other said it was based on what they were taught in school. Those who indicated that they used both riskbased and benefit-based messages interchangeably reported that they do so because they believe that the messages may resonate differently with different people, so they use both hoping that they will reach the individual (50\%), and because they think this method is the most effective at persuading people to breastfeed (31.8\%). Of those who cater their use of risk- or benefit-framed messaging to the individual they are speaking with, most cite the tone of interactions (54.4\%) and consideration of existing feeding plans (31.7\%) as the primary reasons for their choice. When these respondents were asked to identify which individual factors they take into consideration when choosing whether to emphasize the benefits of breastfeeding or the risks of formula feeding with a patient, the most commonly listed factors were the client's attitude about breastfeeding at onset of care $(79.7 \%)$ and current feeding plan (74.7\%). Other significant factors included risk factors for breastfeeding problems and lactational insufficiency (55.7\%) and family support (45.6\%) (Figure 3). 


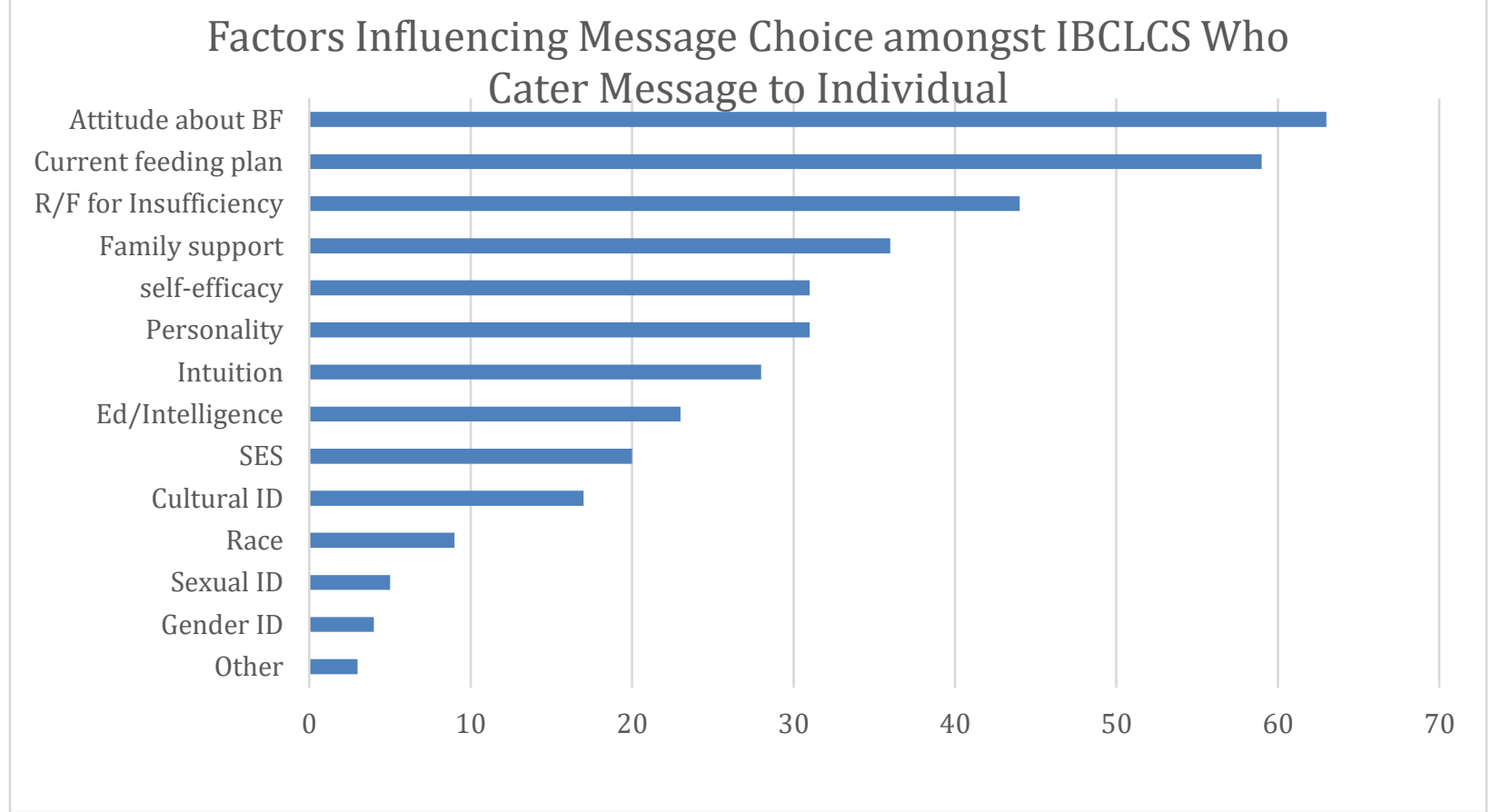

Figure 2:Factors influencing message choice amongst IBCLCs who cater risk messaging to individuals

Benefit-based messaging was the most commonly taught in lactation programs, but there was very little correlation between which type of framing was taught in schools and what lactation consultants ultimately chose to use (Table 2).

Which method people used was not necessarily a strong indication of whether they felt that it was the most effective method. When asked which method they thought was most effective, only $63.3 \%$ of those who used benefit-based messaging thought it was the most effective method, and 2 of the 5 people who reported using risk-based messaging thought it was the most effective (Table 3).

\begin{tabular}{|c|c|c|c|c|c|c|c|c|c|c|}
\hline \multirow{3}{*}{$\begin{array}{l}\text { Which approach do you think is most effective? } \\
\text { Benefits of breastfeeding }\end{array}$} & \multicolumn{8}{|c|}{ Which method do you use? } & & \\
\hline & \multicolumn{2}{|c|}{ The benefits of bfing } & \multicolumn{2}{|c|}{ Risks of formula } & \multicolumn{2}{|c|}{ Both interchangably } & \multicolumn{2}{|c|}{ Depends } & \multicolumn{2}{|c|}{ Total } \\
\hline & 40 & $63.5 \%$ & 0 & $0.0 \%$ & 8 & $36.4 \%$ & 23 & $29.1 \%$ & 71 & $42.0 \%$ \\
\hline Risks of formula feeding & 1 & $1.6 \%$ & 2 & $40.0 \%$ & 2 & $9.1 \%$ & 10 & $12.7 \%$ & 15 & $8.9 \%$ \\
\hline Both are equally effective & 5 & $7.9 \%$ & 0 & $0.0 \%$ & 3 & $13.6 \%$ & 12 & $15.2 \%$ & 20 & $11.8 \%$ \\
\hline There is not enough evidence to determine this & 6 & $9.5 \%$ & 2 & $40.0 \%$ & 7 & $31.8 \%$ & 17 & $21.5 \%$ & 32 & $18.9 \%$ \\
\hline I don't know & 12 & $17.5 \%$ & 1 & $10.0 \%$ & 2 & $9.1 \%$ & 17 & $21.5 \%$ & 31 & $18.3 \%$ \\
\hline & & & & & & & & & 169 & \\
\hline
\end{tabular}

Table 3:Method thought to be more effective by method used

Participants were asked whether their counseling approach had changed over time and what had influenced that change. The majority $(60.4 \%)$ reported that it had changed. 
Those who used benefit-based message framing were the least likely to have changed their practice (Table 4).

\begin{tabular}{|c|c|c|c|c|c|c|c|c|c|c|}
\hline \multirow[b]{2}{*}{ Has your approach changed during your career? } & \multicolumn{8}{|c|}{ What approach do you use? } & & \\
\hline & \multicolumn{2}{|c|}{ Benefits of BF } & \multicolumn{2}{|c|}{ Risks of $\mathrm{FF}$} & \multicolumn{2}{|c|}{ Both } & \multicolumn{2}{|c|}{ Depends } & \multicolumn{2}{|c|}{ Total } \\
\hline Yes & 27 & $42.9 \%$ & 4 & $80.0 \%$ & 15 & $68.2 \%$ & 56 & $70.9 \%$ & 102 & $60.4 \%$ \\
\hline No & 36 & $57.1 \%$ & 1 & $20.0 \%$ & 7 & $31.8 \%$ & 23 & $29.1 \%$ & 67 & $38.6 \%$ \\
\hline
\end{tabular}

Table 4:Reported change in message framing approach by approach used in IBCLCS

The most common reason for change in message framing was information found in conferences and continuing education courses (52.0\%), followed by patient feedback

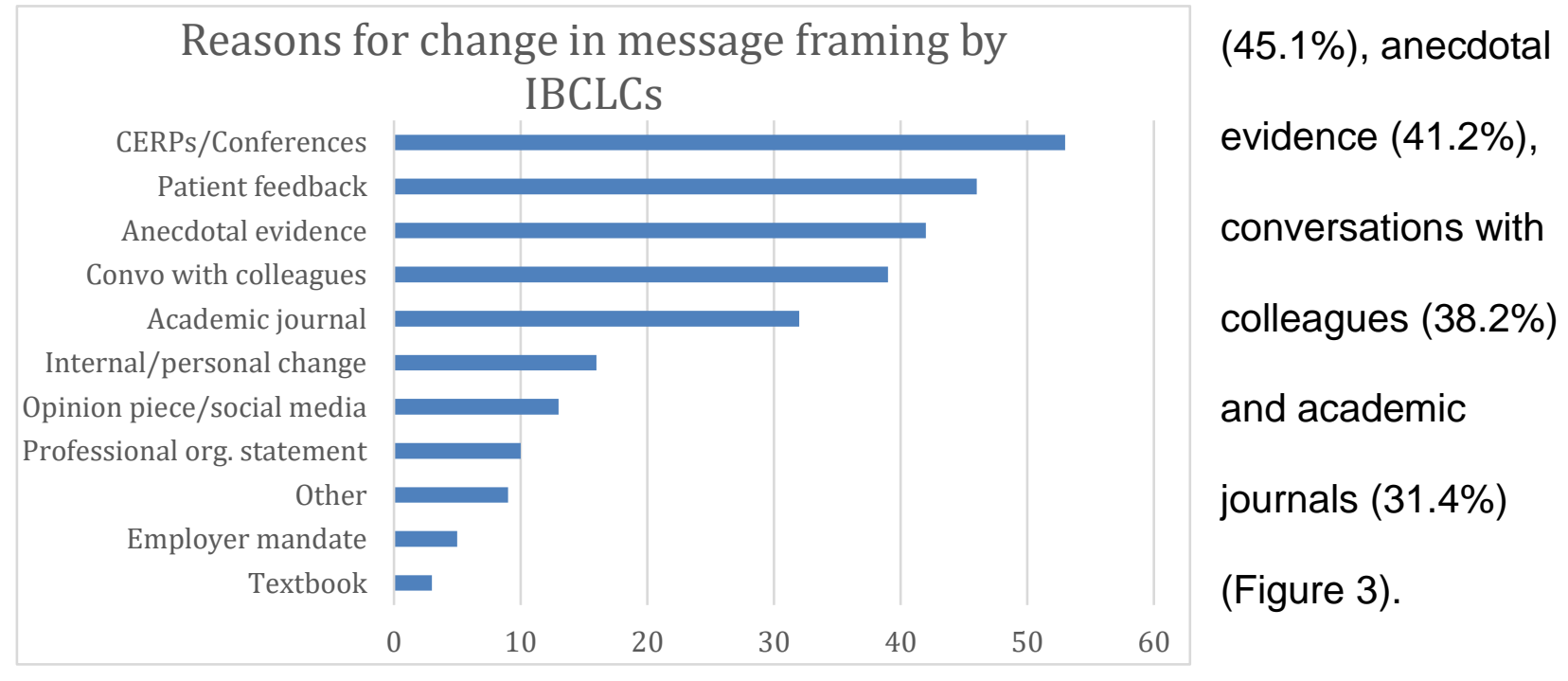

Figure 3: Factors influencing change in message framing amongst IBCLCs in the US

\section{Interview Results}

One of my interview subjects had graduated from an associate degree program in lactation in 2012 and went on to become faculty in the program and was thus able to offer a dual perspective on lactation education. Additionally, she has experience in both private practice and inpatient and outpatient hospital practice at a baby-friendly hospital ${ }^{4}$. She

\footnotetext{
${ }^{4}$ A hospital certified by the Baby Friendly Hospital Initiative, a program administered by the World Health Organization (WHO) and United Nations International Children's Emergency Fund (UNICEF) with an aim to increase the rate of initiation and continuation of breastfeeding worldwide. The baby-friendly certification process requires hospitals to adhere to a set of guidelines about resources they provide patients, hospital protocols, information provision, and counseling techniques.
} 
was taught, and in turn taught her students, to start where the individual is, to establish empathy, and to always add to the patient's knowledge and experience, not to take anything away. This meant that they were instructed to never undermine an individual's confidence or create new fears, but to understand where they were coming from and help them establish a newfound sense of confidence in themselves. This perspective generally led students towards emphasizing benefits rather than risks, and to address risks primarily when information was asked about them. Since beginning work at a babyfriendly hospital, she has been mandated to discuss the risks of formula feeding with families at least once over their course of care. Generally, she said the conversation about the risks of formula tends to come up later in outpatient care or in baby-and-me support groups, when parents are returning to work or beginning solids and seeing a downregulation in their milk supply, which leads them to questions about whether they should supplement and what the risks or disadvantages of that might be. This interviewee highlighted some of her concerns about risk language as follows:

I think parents/lactating people leave the hospital with the idea that breastfeeding is best... I think culturally they understand the risks of formula feeding to a certain extent. And I think parents are made to feel less than if they do have to medically supplement with formula... risk language is sort of detrimental to the dyad... Sometimes calories are the best thing for a breastfeeding dyad and sometimes that's formula or donor milk.

Another student who attended a 4-year university with a lactation program reported having not discussed message framing or the psychology behind convincing people to 
breastfeed. She said that, as a lactation consultant, the assumption was mostly that the person in your office likely already has the drive and desire to breastfeed and it isn't your job to convince them. She too reflected concern over an emphasis on the risks of formula feeding when families were navigating such hostile conditions regarding breastfeeding. She felt that poor social support and need to return to work, coupled with a negative emphasis could cause people to a) put off supplementation too long and b) feel really badly about it when they do supplement.

I interviewed an adjunct instructor at a 4-year public university offering an undergraduate certificate in lactation. She has been an IBCLC for 20 years and practices at a high-risk maternity hospital and children's hospital. She reported guiding the students to follow the parents' lead, generally emphasizing the benefits of breastfeeding, but turning to the risks of formula feeding when they expressed concern about a particular issue. She emphasized the value of education in the prenatal period, noting that it was a less sensitive time, and a great time to build motivation to turn back to when things get tough after the baby is born. She suggested that discussing the risks of formula feeding might be more appropriate in the prenatal time when they are building motivation and less susceptible to feeling guilt or shame. She noted that once families had made the decision to formula feed there was no point in trying to make them feel poorly about it. When asked about the changes she'd noted in risk-messaging in her long career, she noted that now the assumption is that people will breastfeed. Compared to when her career began, lactation support is less about convincing people to breastfeed, and more about identifying and addressing barriers to breastfeeding. 


\section{Limitations:}

This survey was limited by a small sample size $(n=169)$ and that participation was restricted to those in hospital-associated practices, excluding the large number of IBCLCs in private practice. This qualifying criterion was established as an attempt to control for the researcher's immersion in a private practice community who were educated in a similar fashion. I was concerned that responses would be concentrated amongst that community and not be generalizable; however, inclusion of private practice IBCLCs would have created a larger sample and may have provided a more comprehensive view of IBCLC practice. More interviews with students and educators in more diverse geographical areas and programs would have offered a more robust picture of lactation education in the US right now.

\section{Discussion:}

The survey results reveal that, in spite of the professional discourse urging IBCLCs to use risk-based language, most are not choosing this method as their primary method of risk communication. Ultimately, it seems that IBCLCs still find that inclusion of the risks of formula feeding can be an important aspect of practice, but they are sensitive to their audience. Concern over inducing shame, particularly amongst those at high risk for providing formula for physiologic or circumstantial reasons, seems to be a big factor for IBCLCs when deciding which approach to take. Based on the fact that many IBCLCs do not believe that the method they use is the most effective to persuade people to breastfeed, it seems that these approaches are guided more by ethical and philosophical considerations rather than based on perceived efficacy. Most IBCLCs change their 
approach over time, indicating that, like Stuebe, lactation consultants are open to reevaluation of their practices and critical self-assessment, although the directionality of the change could not be clearly identified by the scope of this survey. While work mandates were not a commonly cited reason for choice of message framing, both survey respondents and interviewed IBCLCs working in hospitals stated that mandates associated with the Baby-Friendly Hospital Initiative (BFHI) required them to use riskbased language at least part of the time. Ultimately, most IBCLCs took a nuanced and individualized approach to risk-messaging and did not subscribe to one approach or the other.

At face value the debate about risk message framing may appear to come down to semantics. However, as the background and literature review of this paper have illustrated, there are deep social, emotional, and biological impacts of this debate. Recent media stories have drawn attention to an existing crisis in health inequity for black families in the United States (Villarosa, 2018). Black babies are more than twice as likely to die in the first year of life than white babies. This is relevant to the discussion because breastfeeding can prevent infant deaths. Breastfeeding is protective against SIDS. It lowers the risk of necrotizing enterocolitis in preterm infants and reduces the incidence of and severity of serious lower respiratory infections in infants, as well as gastrointestinal infections like diarrhea (Stuebe, 2009). Increasing breastfeeding amongst black women has the potential to save babies' lives, but is breastfeeding really as much of a modifiable health behavior as we think it is? Is it something that is likely to meaningfully respond to linguistic shifts in counseling or marketing campaigns? 
One of the major takeaways from Lora Wallace and Erin Taylor's study on the efficacy of risk-messaging to change feeding intention was not just that it was ineffective, but that it resulted in negative feelings and distrust towards the message (2016). Given the legacy of racism and medical maltreatment of African Americans in the US, many black people already possess a distrust of medical professionals and the health system (Musa, Schulz, Harris, Silverman \& Thomas, 2009). Using risk-based messaging and guilt to influence black women to breastfeed may further perpetuate the distrust of the medical system, pushing them to avoid care, inducing further stress, and potentially compromising outcomes. Combined with the evidence described by Peters et al. that using threatening messaging with those with low self-efficacy may actually result in downplaying of the risk, defensive denial, and greater risk-taking, it is possible that risk-based messaging may result in African Americans and other oppressed groups being less likely to breastfeed.

From a social justice viewpoint, the impact of message framing as a potential health behavior modifier is a distraction from the social, economic, and structural barriers that families face to actualize positive health behaviors. As Kukla's threshold concept argues, most people know as much as they need to know about the benefits of breastfeeding (or risks of formula feeding). Whether or not they can viably pursue and sustain breastfeeding should be the primary concern of public health and IBCLCs.

It is my conclusion that, while there is philosophical merit in always framing breastfeeding as the norm, from a practical standpoint risk messaging has no demonstrable benefits in 
outcomes and may actually compromise breastfeeding outcomes in vulnerable groups. Framing of breastfeeding messages can be catered to the needs and concerns of the individual but should generally focus on the positives of breastfeeding to avoid instilling guilt or contributing to mental health issues in individuals who are unable to sustain breastfeeding for physiologic or logistical reasons. The value of breastfeeding promotion should not be over-estimated in the contexts that American families live in today, and we must understand that for many families the decision whether to breastfeed is a false choice. The focus needs to shift from a mindset of breastfeeding promotion towards advancing health equity for all Americans, developing universal family leave policies that are representative of our status as a wealthy developed nation, and addressing systemic and interpersonal racism, particularly in the healthcare setting.

\section{Further Research}

Moving forward, research should be conducted directly testing the impact of message framing on lactation outcomes, examining socioeconomic status, race, community and family support, availability of family leave, self-efficacy, and other structural predictors of breastfeeding initiation and continuation as effect modifiers. A more comprehensive examination of IBCLCs' perspectives on message framing and predictors of breastfeeding outcomes could be conducted, as lactation consultants have a unique view into the obstacles lactating people face in establishing and achieving their goals. 


\section{Bibliography}

(2018). The Baby Friendly Hospital Initiative. Baby Friendly USA. Retrieved from: https://www.babyfriendlyusa.org/about/

Baker, J.L., Gamborg, M., Heitmann, B.L., Lissner, L., Sørensen, T.I., Rasmussen, K.M. (2008). Breastfeeding reduces postpartum weight retention. American Journal of Clinical Nutrition. 88(6), 1543-51.

Baker, J.L., Michaelsen, K.F., Rasmussen, K.M.. Sørensen, T.I. (2004). Maternal prepregnant body mass index, duration of breastfeeding, and timing of complementary food introduction are associated with infant weight gain. American Journal of Clinical Nutrition. 80(6), 1579-88.

(2018). Breastfeeding. World Health Organization. Retrieved from: http://www.who.int/topics/breastfeeding/en/

Collaborative Group on Hormonal Factors in Breast Cancer. (2002). Breast cancer and breastfeeding: collaborative reanalysis of individual data from 47 epidemiological studies in 30 countries, including 503012 women with breast cancer and 96973 women without the disease. The Lancet. 360(9328), 187-95

Duijts, L., Jaddoe, V.W., Hofman, A., Moll, H.A. (2010). Prolonged and exclusive breastfeeding reduces the risk of infectious diseases in infancy. Pediatrics. 126(1), 1825.

(2018). Fed is Best foundation. Retrieved from: https://fedisbest.org/

Hauck, F.R., Thompson, J.M., Tanabe, K.O., Moon, R.Y., Vennemann, M.M. (2011). Pediatrics. 128(1), 103-10.

Hirschman, C., Hendershot, G.E. (1979). Trends in breastfeeding among American mothers. Vital and Health Statistics. 3. 1-39.

Horne, R.S., Parslow, P.M., Harding, R. (2004). Respiratory control and arousal in sleeping infants. Paediatric Respiratory Reviews. 5(3), 190-8.

Institute of Medicine Committee on Nutritional Status During Pregnancy and Lactation. (1991). Who breastfeeds in the United States? Nutrition during lactation. (Washington, DC: National Academies Press). 
Ip, S., Chung, M., Raman, G., Trikalinos, T.A., Lau, J. (2009). A Summary of the agency for research and quality's evidence report on breastfeeding in developed countries. Breastfeeding Medicine. 4(1), 17-30

Kahneman, D., Tversky, A. (1979). An analysis of decision under risk. Econometrica. 47(2), 263-291.

Moorman, M., van den Putte, B. (2008). The influence of message framing, intention to quit smoking, and nicotine dependence on the persuasiveness of smoking cessation messages. Addictive Behaviors. 33(10), 1267-1275.

Musa, D., Schulz, R., Harris, R., Silverman, M., \& Thomas, S. B. (2009). Trust in the health care system and the use of preventive health services by older black and white adults. American journal of public health, 99(7), 1293-9.

Newburg, D.S., Walker, W.A. (2007). Protection of the neonate by innate immune system of developing gut and human milk. Pediatric Research. 61(1), 2-8.

Office of the Surgeon General, Center for Disease Control, Office on Women's Health. (2011). A Surgeon General's call to action to support breastfeeding. (Rockville, MD: Office of the Surgeon General).

O'Keefe, D.J. (2012). Lessons from the story of gain-framed and loss framed persuasive messages. In $\mathrm{H}$. Cho (Ed.). Health Communication Message Design. (Los Angeles:SAGE Publications). 3-20.

Owen, C.G., Whincup, P.H., Cook, D.G. (2011). Breastfeeding and cardiovascular risk factors and outcomes in later life: evidence from epidemiological studies. Proceedings of the Nutrition Society. 70(4), 478-84

Peters, G-J. Y., Ruiter, R.A.C., Kok, G. (2013). Threatening communication: a critical reanalysis and a revised meta-analytic test of fear appeal theory. Health Psychology Review. 7(1), 8-31.

(2018). Rates of any and exclusive breastfeeding by socio-demographics among children born in 2015. Center for Disease Control. Retrieved from: https://www.cdc.gov/breastfeeding/data/nis data/rates-any-exclusive-bf-socio-dem2015.htm 
Schwarz, E.B., Brown, J.S., Creasman, J.M., Stuebe, A., McClure, C.K., Van Den Eeden, S.K., Thom, D. (2010). Lactation and maternal risk of type 2 diabetes: a population based study. American Journal of Medicine. 123(9), 863.e1 - 863.e6.

Smith, P.H. (2018). Social justice at the core of breastfeeding protection, promotion and support: A conceptualization. Journal of Human Lactation. 34(2), 220-225.

Smith, J., Dunstone, M., Elliott-Rudder, M. (2009). Health professional knowledge of breastfeeding: Are the health risks of infant formula feeding accurately conveyed by the titles and abstracts of journal articles? Journal of Human Lactation. 25 (3), 350-359.

Spatz, D.L., Lessen, R. (2011). Risks of not breastfeeding. International Lactation Consultant Association. Retrieved from: http://www.ilca.org/learning/resources

Stuebe, A. (2016). Might there be risks of risk-based language? Breastfeeding Medicine. Retrieved from: https://bfmed.wordpress.com/2016/04/13/might-there-berisks-of-risk-based-language/

Stuebe, A. (2009). The risks of not breastfeeding for mothers and infants. Reviews in Obstetrics \& Gynecology. 2(4), 222-231.

Stuebe, A. (2016). Update: Research studies quantify risks of risk-based language. Breastfeeding medicine. Retrieved from:

https://bfmed.wordpress.com/2016/05/04/update-reseach-studies-quantify-risks-of-riskbased-language/

Stuebe, A. (2010). Why we still need to watch our language. Breastfeeding Medicine. Retrieved from: https://bfmed.wordpress.com/2010/05/03/why-we-still-need-to-watchour-language/

Taylor, E.N., Wallace, L.E. (2012) For shame:Feminism, breastfeeding advocacy, and maternal guilt. Hypatia. 27(1), 76-98

Thulier, D., Mercer, J. (2009). Variables associated with breastfeeding duration. Journal of Obstetric, Gynecologic \& Neonatal Nursing. 38(3), 259-268.

Toll, B.A., Salovey, P., O'Malley, S.S., Mazure, C.M., Latimer, A., McKee, S.A. (2008) Message framing for smoking cessation: the interaction of risk perceptions and gender. Nicotine \& Tobacco Research. 10(1), 195-200. 
Turner, M.M. (2012) Using emotional appeals in health messages. In H. Cho (Ed.). Health Communication Message Design. (Los Angeles:SAGE Publications). 59-71.

Villarosa, L. (2018). Why America's black mothers and babies are in a life-or-death crisis. The New York Times. Retrieved from:

https://www.nytimes.com/2018/04/11/magazine/black-mothers-babies-death-maternalmortality.html

Wallace, L.E., Taylor, E.N. (2016). Running a risk: Expectant mothers respond to "risk" language in breastfeeding promotion. Women's Reproductive Health, 3 (1), 16-29.

Wiessinger, D. (1996). Watch Your Language! Journal of Human Lactation. 12(1), 